\title{
The growth and carcass and meat characteristics of pigs raised in a free-range or conventional housing system
}

\author{
L.C. Hoffman ${ }^{1 \#}$, E. Styger ${ }^{1,2}$, M. Muller ${ }^{2}$ and T.S. Brand ${ }^{1,3}$ \\ ${ }^{1}$ Department of Animal Sciences, ${ }^{2}$ Department of Consumer Science, University of Stellenbosch, Private Bag X1, \\ Matieland 7602, South Africa \\ ${ }^{3}$ Elsenburg Agricultural Research Centre, Private Bag X1, Elsenburg 7607, South Africa
}

\begin{abstract}
The growth performance and the carcass and physical and chemical characteristics of the meat of 24 Landrace X Large White pigs were compared when reared under a free-range or a conventional housing system. The free-range pigs had lower feed intakes and slower growth rates than the conventionally housed pigs. The free-range pigs also had a lower $\mathrm{P}_{2}$ fat depth and therefore yielded a carcass with a higher percentage lean meat. Housing systems had no effect on the weight distribution of the commercial cuts (as a percentage of cold carcass weight). The meat from the free-range pigs was slightly more reddish in colour, but apart from that housing systems had no effect on the water-holding capacity (WHC) of the meat, its initial $\mathrm{pH}\left(\mathrm{pH}_{45}\right)$ or its final $\mathrm{pH}\left(\mathrm{pH}_{24}\right)$. The meat from the free-range pigs had the same shear force (WBS) values as those of the conventionally housed pigs. Housing systems had an influence on the fatty acid composition. Stearic acid (C18:0) was significantly lower in the meat of the free-range pigs than that of the conventionally housed pigs while linoleic acid (C18:2n-6) and polyunsaturated fatty acid (PUFA) concentrations were significantly higher. However, the moisture, fat, protein and ash contents as well as the mineral composition in the meat were unaffected by housing systems. It could be concluded that pigs raised in a conventional housing system produced meat with similar quality characteristics to that of pigs raised in a free-range housing system.
\end{abstract}

Keywords: Free-range, housing systems, growth performance, carcass yield, physical quality, chemical composition

${ }^{\#}$ Corresponding author. E-mail: 1ch@sun.ac.za

\section{Introduction}

The 'ethical' management of animals, in particular that of animals produced in intensive systems, is becoming a more important issue throughout the entire animal industry. In the past few years there has been commercial interest in animal products originating from animal systems that could be considered 'natural' or 'traditional'. Some consumers do not consider modern intensive animal production systems synonymous with product quality (Barton Gade, 2002). There is also an increasing perception amongst consumers that there is widespread use of synthetic chemicals, both in medication and as growth promoters, in pig feed components (Barton Gade, 2002).

Intensive animal production systems, such as those practised in pig and poultry production, are being questioned by animal welfare groups, as these animals are bred, housed and fattened to slaughter in total confinement, an environment perceived to be unnatural (Sather et al., 1997). The restriction of the animals from behaving naturally may lead to behavioural problems and aggression (Barton Gade, 2002). Warriss et al. (1983) and Beattie et al. (2000) suggested that pigs housed in a barren environment might be more susceptible to stress, which may affect the quality of pork. However, the management of conventional systems is more efficient in terms of controlling diseases and treating individual animals (Barton Gade, 2002). On the other hand, the advantage of free-range systems is that these animals have more freedom to express natural behaviour patterns. As such, these animals are less likely to behave aggressively and may be less susceptible to stress which may result in a better pork quality (Beattie et al., 2000). However, the control in the environment in free-range systems is much more difficult with regard to the control and treatment of animals for diseases (Barton Gade, 2002). Therefore, there are some welfare and management advantages and disadvantages in both free-range and conventional housing systems which may positively or negatively influence the quality of pork.

Consumers, especially those from Europe, have an underlying desire to purchase pork products with some social attributes or with certain social assurances such as protection of the environment, ethical rearing 
of the animals, development of the small farmer, etc. (Windhorst, 2001). A segment of consumers is willing to pay more for pork products with social assurances, even if improvements in sensory features are not expected or directly included in the presentation of the pork product (Gentry et al., 2001). There are, however, some consumers who associate free-range products with a better taste and nutritional value than conventionally produced products (Nilzén et al., 2001). This obviously opens niche markets for naturally produced pork.

The effect of housing systems on pork quality are inconclusive, though some studies showed benefits in housing outdoors (Beattie et al., 2000), while others showed benefits from pigs housed indoors (Enfält $e t$ al., 1997; Sather et al., 1997). Enfält et al. (1997) and Sather et al. (1997) concluded that the meat derived from the outdoor housed pigs had a lower ultimate $\mathrm{pH}$, higher drip loss (lower water-holding capacity) and higher shear force values than pigs housed indoors. These researchers also recorded higher percentages of lean meat from pigs housed outdoors, and consequently less tender meat. On the other hand, Beattie et al. (2000) reported that pigs from an enriched environment, e.g. access to field plants and outdoor housing, produced pork with greater tenderness (lower shear force values) than pigs raised in a barren environment. Warriss et al. (1983) and Van der Wal et al. (1993), however, found no difference in water-holding capacity or ultimate $\mathrm{pH}$ from indoor or outdoor housed pigs.

Studies comparing indoor and outdoor housing systems have thus produced inconsistent results and it appears that both positive and negative influences of free-range housing systems on pork quality might be obtained. The aim of this study was to compare the production potential and carcass yield, as well as the physical and chemical meat composition of pigs raised either in a conventional or in a free-range housing system. Such a study has not been performed under South African conditions, specifically in the Western Cape area.

\section{Materials and Methods}

Twenty-four Landrace X Large White pigs (12 gilts and 12 boars) were divided equally (pertaining to sex) into two subgroups: a free-range (housed outdoors, FR) and conventionally housed (housed indoors, Conv) pigs. The pigs $(27.65 \pm 3.757 \mathrm{~kg}$ live weight $)$ were randomly selected out of six litters of similar aged weaners that had been housed together in a weaning facility. They were obtained from a commercial producer in the Western Cape and raised at the Elsenburg Agricultural Research Centre from September to November 2000 (spring, early summer period mean temperatures ranging between 14 and $28^{\circ} \mathrm{C}$ ). The freerange pigs were housed as a group in an $1800 \mathrm{~m}^{2}$ pen. This pen had a group of conifers that provided shade as well as an A-frame hut $(1.5 \mathrm{~m} \mathrm{x} 1.5 \mathrm{~m})$ built on the ground with a straw roof. The A-frame hut was filled with straw that was replaced as required. The other group of pigs was housed indoors in a $100 \mathrm{~m}^{2}$ pen. This pen formed part of a group of pens that were inside a pig grower's shed. This shed was enclosed with walls and had a roof - manually opening or closing windows controlled airflow. The floor of the pen was concrete with a third of the pen being concrete slats above the faeces and urine drainage channel. Both groups received the same commercial diet ad libitum (13.8 MJ DE $/ \mathrm{kg}, 170 \mathrm{~g}$ protein $/ \mathrm{kg} ; 10 \mathrm{~g}$ lysine $/ \mathrm{kg}$ feed) from the same type of self-feeder and had free access to water (nipple supply). Every 14 days each individual pig was weighed and the back fat thickness ( $\mathrm{P}_{2}$ fat measurement) was taken ultrasonically at the last rib, $45 \mathrm{~mm}$ from the spine. Feed intake was measured for each group of pigs. Both groups were slaughtered after 81 days in the trial. Prior to being slaughtered, feed was withheld for $10 \mathrm{~h}$, but water was supplied until loading and transportation. The pigs were weighed again after the $10 \mathrm{~h}$ feed withdrawal period to record empty live weight. No electrical prodders were used to handle the pigs at any stage. Loading and transportation were done under conditions of minimal stress. This involved early morning transportation to avoid high temperatures, no overcrowding and no mixing of unfamiliar groups. Two vehicles were used in tandem. Transportation by road to the slaughter facility took approximately $15 \mathrm{~min}$. The pigs were kept in lairage for approximately $1 \mathrm{~h}$ prior to slaughtering on the same day, the one group being slaughtered immediately after the other. The pigs were slaughtered according to standard commercial procedures. The latter consisted of electrical stunning ( $250 \mathrm{~V} \mathrm{AC}$, ear to ear for 3-5 s) and sticking within $30 \mathrm{~s}$. Thereafter the pigs were eviscerated and inspected by the appropriate government health official. The $\mathrm{P}_{2}$ fat measurement was taken on each carcass with an intrascope between the $2^{\text {nd }}$ and $3^{\text {rd }}$ last rib, $45 \mathrm{~mm}$ from the carcass midline. This measurement was used to calculate the percentage lean meat yield of each carcass using the formula: lean\% $=74.4367-0.4023 \mathrm{X}_{1}$, where $\mathrm{X}_{1}=$ fat-thickness in $\mathrm{mm}$ (Government Notice No. $\left.\mathrm{R} 1748,1992\right)$.

Each carcass was weighed warm and after chilling $\left(2{ }^{\circ} \mathrm{C}\right.$ for $\left.24 \mathrm{~h}\right)$. Forty-five minutes post mortem, the initial $\mathrm{pH}$ was taken $\left(\mathrm{pH}_{45}\right)$ and after the $24 \mathrm{~h}$ chilling period, the ultimate $\mathrm{pH}\left(\mathrm{pH}_{24}\right)$ was measured. The 
$\mathrm{pH}$ measurements were taken on the M. longissimus lumborum (MLL) between the $2^{\text {nd }}$ and $3^{\text {rd }}$ lumbar vertebrae counting from the caudal end. The $\mathrm{pH}$ was measured with a penetrating glass electrode on a handheld Crison $\mathrm{pH} / \mathrm{mV}-506$ meter. The $\mathrm{pH}$ meter consisted of an automatic temperature compensator to ensure the adjustment of the $\mathrm{pH}$ for temperature. The $\mathrm{pH}$ meter was rinsed with distilled water after every reading and re-calibrated after every fourth reading.

After a chilling period of $24 \mathrm{~h}$, the head was removed between the junction of the axis and atlas bones by means of a sharp knife. Thereafter, the removal of the primal cuts (shoulder, belly, back and legs) from the carcasses was done on a stationary band saw. The shoulder was removed by cutting caudally through the $5^{\text {th }}$ and $6^{\text {th }}$ thoracic vertebrae, with the front trotter removed by cutting through the metacarpal region (at the joint of the carpal bones and the radius and ulna). The backs (M. longissimus dorsi) and bellies were removed from the carcasses by cutting caudally at a line perpendicular to the spinal column, between the last lumbar and first sacral vertebrae. Sawing along the natural midline between the legs to split the two legs. The trotter was removed from the ham at the distal end of the tibia and fibula parallel to the cut made to remove the leg from the carcass. Sawing along the spinal column split the remaining carcass. Thereafter, the belly was removed from the back by cutting in a line parallel to the spinal column, $c a .18 \mathrm{~cm}$ from the spinal column (Fisher et al., 2000).

For the physical and chemical analyses, the MLL (from the $1^{\text {st }}$ to the last lumbar vertebrae) was removed from one of the backs, and trimmed of all visible subcutaneous fat. For the determination of the drip loss, $1.5 \mathrm{~cm}$ thick meat samples, cut perpendicular to the longitudinal axis of the muscle on the caudal side of the removed MLL, were weighed. Drip loss was determined according to the procedure described by Honikel (1998) with the samples weighed individually (approximately $110 \mathrm{~g}$ ) and placed under atmospheric pressure in a net enclosed in a polythene bag in such a manner that the exudate did not come into contact with the sample, but collected in the bag. After a storage period of $24 \mathrm{~h}$ at $4{ }^{\circ} \mathrm{C}$, the samples were dried and weighed again and drip loss was expressed as a percentage of the initial weight (Honikel, 1998). For cooking loss determination, samples were freshly cut (in the position next to that removed for drip loss determination) and weighed (initial weight). Individual slices of approximately $110 \mathrm{~g}$ (in thin-walled plastic bags) were placed in a water-bath at $75{ }^{\circ} \mathrm{C}$. After one hour the samples were removed from the water-bath and cooled in cold water. The meat was removed from the bag, blotted dry, weighed and cooking loss was expressed as a percentage of the initial sample weight (Honikel, 1998). The cooking loss samples were also used to determine shear force values. Toughness was measured as the maximum force (N/1.27 cm diameter) required to shear a $1.27 \mathrm{~cm}$ diameter cylindrical core (five cores per MLL sample per pig) of cooked meat perpendicular to the grain, at a crosshead speed of $200 \mathrm{~mm} / \mathrm{min}$. The shear force measurements were generated with a Warner-Bratzler shear attachment, fitted to an Instron Universal Testing Machine. A higher reading indicated greater shear force and therefore tougher meat.

Prior to using the MLL sample for cooking loss determination, the sample was allowed to bloom for 20 mins, whereafter three readings per sample (on the cut surface perpendicular to the longitudinal axis of the muscle) were taken for colour determination. Colour was evaluated according to the method described by Honikel (1998) using a Colorgard System 2000 colorimeter (Pacific Scientific, Silver Spring, MD, USA) to determine $L^{*}, a^{*}$ and $b^{*}$ values with $L^{*}$ indicating lightness, $a^{*}$ the red-green range and $b^{*}$ the blueyellow range. These values were also used to calculate the chroma value and hue angle according to the

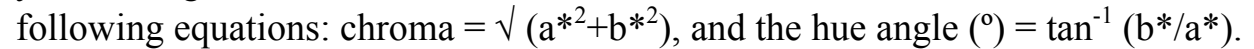

Proximate chemical analyses were conducted on the fresh MLL samples. The frozen muscle samples were cut into smaller portions, minced three times through a $2 \mathrm{~mm}$ sieve to ensure homogeneity, and chemically analysed. Total concentrations of moisture, protein and ash were determined according to standard AOAC methods (AOAC, 1995). The protein ( $\mathrm{N} \mathrm{x} \mathrm{6.25)} \mathrm{content} \mathrm{was} \mathrm{determined} \mathrm{by} \mathrm{the} \mathrm{block}$ digestion method (AOAC, 1997) and ashing was done at $500{ }^{\circ} \mathrm{C}$ for a period of $5 \mathrm{~h}$. The moisture content was analysed by drying a $2.5 \mathrm{~g}$ sample at $100^{\circ} \mathrm{C}$ for a period of $24 \mathrm{~h}$. The total fat content was determined by extracting the fat with a 2:1 mixture of chloroform: methanol (Lee et al., 1996).

After the extraction of the lipids, the fatty acid methyl esters (FAME) were prepared according to the procedures published by Morrison \& Smith (1964). The FAME were analysed with a gas-liquid chromatograph (Varian Model 3300), equipped with flame ionisation detection and two $30 \mathrm{~m}$ fused silica megabore DB-225 columns of $0.53 \mathrm{~mm}$ internal diameter (J\&W Scientific, Folsom, CA). Gas flow rates were hydrogen $25 \mathrm{ml} / \mathrm{min}$ and nitrogen (carrier gas) $5-8 \mathrm{ml} / \mathrm{min}$. The temperature programme was linear at 4 ${ }^{\circ} \mathrm{C} / \mathrm{min}$ with initial and final temperatures of $160{ }^{\circ} \mathrm{C}$ and $220^{\circ} \mathrm{C}$ (held for $10 \mathrm{~min}$ ), respectively. The injector 
temperature was $240{ }^{\circ} \mathrm{C}$ and the detector temperature $250{ }^{\circ} \mathrm{C}$. The FAME was identified by comparison with the retention times of a standard FAME mixture (Nu-Chek-Prep Inc., Elysian, Minnesota).

A wet ashing method was used to prepare the samples for mineral analyses according to Method IIA of Watson (1994) and involves the boiling of the samples in concentrated nitric acid and perchloric acid. The concentrations of calcium $(\mathrm{Ca})$, copper $(\mathrm{Cu})$, iron $(\mathrm{Fe})$, potassium $(\mathrm{K})$, magnesium $(\mathrm{Mg})$, sodium $(\mathrm{Na})$, phosphorus $(\mathrm{P})$, lead $(\mathrm{Pb})$ and zinc $(\mathrm{Zn})$ of the digestates were determined by direct current plasma emission spectrometry (Pinta, 1982).

The experiment consisted of a completely randomised design with two treatments (housing systems and sex). Analysis of variance (ANOVA) was performed on all the variables using the SAS Version 8.12 (SAS, 1990). The Shapiro-Wilk test was performed to test for non-normality (Shapiro \& Wilk, 1965). In some cases deviations from normality were the cause of one or two outliers, which were removed before the final analysis. Where there was still significant evidence of non-normality, this could be ascribed to kurtosis rather than skewness. Student's t-least significant difference (LSD) was calculated at a 5\% significance level to compare treatment comparison of means.

\section{Results and Discussion}

For all the parameters tested there was no housing system $x$ sex interaction. Sex had no influence on any of the parameters and the data were therefore pooled to test for the main effect of housing systems. As a group the free-range pigs consumed $1330 \mathrm{~kg}$ of feed $(1368.31 \mathrm{~g} / \mathrm{pig} /$ day $)$, while the group of conventionally housed pigs consumed $1655 \mathrm{~kg}(1702.27 \mathrm{~g} / \mathrm{pig} /$ day). This gave a calculated feed conversion ratio (FCR) of 2.17 and $2.35 \mathrm{~kg}$ feed per $\mathrm{kg}$ live weight gain, respectively. When the pigs were loaded onto the truck, it was noted that the free-range housed pigs had mosquito bites and fleas. It was also observed that the free-range housed pigs who had little contact with humans, seemed more stressed when they were loaded for transport to the abattoir than the conventionally reared ones. Similar findings were recorded by Hemsworth et al. (2002), who noted that free-range pigs showed a stronger fear response towards humans during the loading activity than conventionally reared ones. In contrast, the results of Warriss et al. (1983) showed that although free-range pigs were more easily startled than conventionally housed pigs, the latter were much more difficult to load into trucks than free-range housed pigs. Barton Gade \& Blaabjerg (1989) also found that free-range pigs were calmer and handled easier in the abattoir than conventionally reared pigs.

The growth and carcass characteristics of the pigs from the free-range and conventionally housed systems can be seen in Table 1. Although there was no significant difference between the initial live weight and initial $\mathrm{P}_{2}$ measurements of the two housing systems, the conventionally housed pigs had a significantly higher weight gain $(\mathrm{P}=0.035)$ as well as a significantly higher increase in subcutaneous fat $\left(\mathrm{P}_{2}\right)(\mathrm{P}=0.01)$.

The average daily gain (ADG) of the free-range pigs was significantly lower $(0.639 \pm 0.0605 \mathrm{~kg})$ than that of the conventionally housed pigs $(0.725 \pm 0.1255 \mathrm{~kg})$. This agrees with the findings of Enfält et al. (1997) and Sather et al. (1997), that conventionally housed pigs grow faster compared to free-range pigs. There was a tendency for the conventionally housed pigs to have both a higher warm $(P=0.067)$ and cold $(P$ $=0.057)$ dressed weight, but neither warm nor cold dressing percentage differed significantly between the two housing systems. Warriss et al. (1983) also found that the housing systems had no significant effect on dressing percentage. However, Sather et al. (1997) found a higher dressing percentage in conventionally housed pigs during the summer season, but during the winter season there were no differences among freerange and conventionally housed pigs. The two housing systems did not influence the amount of moisture lost during the cooling regimen in the present investigation.

The carcasses of the conventionally housed pigs had higher $(\mathrm{P}=0.051) \mathrm{P}_{2}$ fat values and, therefore, lower $(\mathrm{P} \leq 0.05)$ calculated lean meat percentages $(69 \%)$ than the free-range pigs $(70 \%)$. Warriss et al. (1983), Enfält et al. (1997) and Sather et al. (1997) noted that free-range pigs had lower percentages of back fat thickness (lower $\mathrm{P}_{2}$ fat values) compared to indoor housed pigs. However, both the effects can be attributed to the higher body weight (Hoffman et al., 1991) of the conventionally housed pigs compared to the free-range pigs.

Although there was a tendency for the conventionally housed pigs to have higher cold carcass weights, when the commercial cuts were expressed as a percentage of cold carcass weight, there were no significant differences $(\mathrm{P}>0.05)$ between the two housing systems. These commercial yields are similar to those noted by Fisher et al. (2000) for South African commercial hybrids. 
Table 1 The growth and carcass characteristics of pigs ( $\mathrm{ca} .28-85 \mathrm{~kg}$ ) raised either in a free-range or in a conventional housing system (Mean \pm s.d.)

\begin{tabular}{|c|c|c|c|}
\hline \multicolumn{4}{|c|}{ Housing systems } \\
\hline & Conv $(n=12)$ & $\mathrm{FR}(\mathrm{n}=12)$ & $\mathrm{P}$ \\
\hline Initial body weight $(\mathrm{kg})$ & $27.67 \pm 3.601$ & $27.63 \pm 4.068$ & 0.983 \\
\hline Final body weight $(\mathrm{kg})$ & $86.38 \pm 11.670$ & $78.67 \pm 6.783$ & 0.064 \\
\hline Weight gain $(\mathrm{kg})$ (over 81-day period) & $58.71 \pm 10.163$ & $51.60 \pm 5.600$ & 0.035 \\
\hline Average daily gain ( $\mathrm{kg} /$ day) & $0.725 \pm 0.1255$ & $0.639 \pm 0.0605$ & 0.049 \\
\hline Initial $\mathrm{P}_{2}(\mathrm{~mm})$ & $5.75 \pm 1.357$ & $4.75 \pm 1.485$ & 0.099 \\
\hline Final $P_{2}(\mathrm{~mm})$ & $14.08 \pm 1.621$ & $11.25 \pm 1.815$ & 0.001 \\
\hline $\mathrm{P}_{2}$ gain $(\mathrm{mm})$ & $8.33 \pm 1.557$ & $6.50 \pm 1.784$ & 0.010 \\
\hline Warm carcass weight (kg) & $67.17 \pm 9.833$ & $60.92 \pm 4.963$ & 0.067 \\
\hline Cold carcass weight (kg) & $66.00 \pm 9.553$ & $59.68 \pm 4.795$ & 0.057 \\
\hline Weight loss (kg) & $1.17 \pm 0.458$ & $1.23 \pm 0.339$ & 0.690 \\
\hline a Dressing percentage (\%) & $77.70 \pm 1.591$ & $77.49 \pm 1.986$ & 0.780 \\
\hline${ }^{\mathrm{b}}$ Dressing percentage (\%) & $76.36 \pm 1.475$ & $75.92 \pm 1.945$ & 0.548 \\
\hline${ }^{\mathrm{c}} \mathrm{P}_{2}$ carcass $(\mathrm{mm})$ & $12.83 \pm 2.209$ & $10.75 \pm 2.701$ & 0.051 \\
\hline Calculated lean meat (\%) & $69.27 \pm 0.889$ & $70.11 \pm 1.087$ & 0.051 \\
\hline d Shoulder weight (\%) & $13.65 \pm 1.811$ & $13.70 \pm 0.745$ & 0.927 \\
\hline${ }^{\mathrm{d}}$ Back weight $(\%)$ & $7.40 \pm 0.400$ & $7.30 \pm 0.374$ & 0.688 \\
\hline d Leg weight (\%) & $15.60 \pm 0.646$ & $15.37 \pm 0.552$ & 0.389 \\
\hline dBelly weight (\%) & $6.03 \pm 0.532$ & $5.75 \pm 0.392$ & 0.157 \\
\hline
\end{tabular}

\footnotetext{
${ }^{\mathrm{a}}$ Warm carcass weight as a percentage of live weight

${ }^{\mathrm{b}}$ Cold carcass weight as a percentage of live weight

${ }^{c}$ Fat depth measured between the $2^{\text {nd }}-3^{\text {rd }}$ last rib, $45 \mathrm{~mm}$ in from the midline

${ }^{\mathrm{d}}$ As a percentage of cold carcass weight

Conv $=$ Conventionally housed pigs

$\mathrm{FR}=$ Free-range housed pigs
}

The physical meat quality attributes (water-holding capacity, shear force values, colour measurements and $\mathrm{pH}$ values) of the pigs from the two housing systems are depicted in Table 2. Neither cooking loss nor drip loss differed significantly $(\mathrm{P}>0.05)$ between the free-range and conventionally housed pigs. Van der Wal et al. (1993) also found no differences in water-holding capacity between regular and free-range housed pigs. There was also no difference $(\mathrm{P}=0.735)$ in the shear force (WBS) values of the two housing systems, which indicates that there were no differences in the physical tenderness of the meat. However, Enfält et al. (1997) found outdoor housed pigs to have a higher drip loss and higher shear force values than those of indoor housed pigs. The $\mathrm{a}^{*}$ values of the free-range pigs were significantly higher $(\mathrm{P}=$ 0.043), indicating that the meat was more reddish in colour (also shown by the hue and chroma values) than that of the conventionally housed pigs. None of the other colour parameters differed statistically. In their study Warriss et al. (1983) reported that housing pigs outdoors resulted in a darker meat colour than it did in a conventionally housed system. Pigs are born with a predominance of Type 1 (darker red) fibres and as they develop there is a shift to Type IIA and Type IIB fibres (Gentry et al., 2001). These researchers noted that pigs in an outdoor system tend to have more of Type I muscle fibres at processing than pigs bred and housed indoors. The muscle $\mathrm{pH}$ values $\left(\mathrm{pH}_{45}\right.$ and $\left.\mathrm{pH}_{24}\right)$ were not influenced by the two housing systems. However, Sather et al. (1997) found that initial muscle $\mathrm{pH}$ of free-range housed pigs tended to be lower than 
that of conventionally housed pigs. Results of Barton Gade \& Blaabjerg (1989) and Enfält et al. (1997) showed that free-range pigs had lower ultimate $\mathrm{pH}$ measurements compared to the indoor housed pigs. Therefore, Barton Gade (1987) suggested that free-range pigs had a tendency to produce higher levels of pale, soft and exudative (PSE) meat than conventionally housed pigs. These researchers reasoned that freerange pigs had higher levels of muscle glycogen than their pen-housed counterparts, which resulted in lower $\mathrm{pH}$ readings.

Table 2 Water-holding capacity, shear force values, colour measurements and $\mathrm{pH}$ values of the M. longissimus lumborum (MLL) from the free-range and conventionally housed pigs (Mean \pm s.d.)

\begin{tabular}{|c|c|c|c|}
\hline \multicolumn{4}{|c|}{ Housing systems } \\
\hline & Conv $(\mathrm{n}=12)$ & $\mathrm{FR}(\mathrm{n}=12)$ & $\mathrm{P}$ \\
\hline Cooking loss $(\%)$ & $22.59 \pm 3.026$ & $23.97 \pm 4.036$ & 0.354 \\
\hline Drip loss $(\%)$ & $4.11 \pm 1.223$ & $3.91 \pm 0.891$ & 0.656 \\
\hline Shear force $(\mathrm{N} / 1.27 \mathrm{~cm}$ diameter) & $117.20 \pm 12.045$ & $115.48 \pm 12.465$ & 0.735 \\
\hline Colour L* & $55.32 \pm 3.078$ & $53.98 \pm 1.912$ & 0.213 \\
\hline$a^{*}$ & $2.81 \pm 0.666$ & $3.46 \pm 0.820$ & 0.043 \\
\hline$b^{*}$ & $10.10 \pm 0.690$ & $10.47 \pm 0.672$ & 0.196 \\
\hline Hue $\left({ }^{\circ}\right)$ & $74.46 \pm 3.760$ & $71.76 \pm 4.122$ & 0.108 \\
\hline Chroma & $10.48 \pm 0.959$ & $11.03 \pm 1.060$ & 0.200 \\
\hline $\mathrm{pH}_{45}$ & $6.16 \pm 0.418$ & $6.22 \pm 0.391$ & 0.724 \\
\hline $\mathrm{pH}_{24}$ & $5.53 \pm 0.138$ & $5.52 \pm 0.146$ & 0.966 \\
\hline $\begin{array}{l}\mathrm{L}^{*}=\text { Lightness; } \mathrm{a}^{*}=\text { redness } ; \mathrm{b}^{*}= \\
\text { Conv = Conventionally housed pig } \\
\text { FR = Free-range pigs }\end{array}$ & llowness & & \\
\hline
\end{tabular}

Comparisons of the means for the proximate chemical composition of the MLL derived from the free-range and conventionally housed pigs are presented in Table 3. No significant differences $(\mathrm{P}>0.05)$ were found with regard to moisture, fat, protein and ash content of the MLL between the two housing systems. There was a tendency for the meat from the free-range pigs to have a lower fat content (intramuscular fat, IMF) (1.52\%) compared to the meat from the conventionally housed pigs (1.82\%). This trend correlates with the thicker back fat $\left(\mathrm{P}_{2}\right.$ measurement, Table 2$)$ of the conventionally housed pigs and thus corresponds to the development of the various different depots due to the growth of the pigs. This tendency is consistent with the results of Warriss et al. (1983), who found that pigs housed outdoors had significantly thinner back fat than the pigs housed indoors. These researchers also stated that the difference in back fat possibly illustrated the use of a corresponding amount of energy for the maintenance of body temperature and motor activity. Therefore, this tendency was not present to the same degree in the pigs housed indoors. Results of Enfält et al. (1997) also showed that the meat from pigs housed outdoors had less IMF compared to that of indoor housed pigs. 
Table 3 Comparison of the means for the proximate chemical composition of the M. longissimus lumborum (MLL) between the freerange and conventionally housed pigs ( $\mathrm{g} / 100 \mathrm{~g}$ meat sample) (Mean \pm s.d.)

\begin{tabular}{llll}
\hline \multicolumn{4}{c}{ Housing systems } \\
\hline Conv (n=12) & FR (n=12) & P \\
\hline Moisture & $74.54 \pm 0.913$ & $74.79 \pm 1.312$ & 0.592 \\
Lipid & $1.82 \pm 0.491$ & $1.52 \pm 0.619$ & 0.206 \\
Protein & $22.31 \pm 1.194$ & $22.83 \pm 0.710$ & 0.212 \\
Ash & $1.20 \pm 0.141$ & $1.29 \pm 0.203$ & 0.226 \\
\hline \multicolumn{2}{l}{ Conv = Conventionally housed pigs } & & \\
FR = Free-range pigs & & &
\end{tabular}

Comparison of the means for the fatty acid composition of the MLL derived from the free-range and conventionally housed pigs is presented in Table 4. Palmitic acid (C16:0) was the most abundant SFA and oleic acid (C18:1n-9) the mono-unsaturated fatty acids (MUFA) and linoleic acid (C18:2n-6) the polyunsaturated fatty acids (PUFA) for the muscle of the pigs housed in both systems.

Stearic acid $(\mathrm{C} 18: 0)$, one of the major SFA differed significantly $(\mathrm{P} \leq 0.05)$ between the two housing systems. The free-range pigs had a lower $(\mathrm{P} \leq 0.05) \mathrm{C} 18: 0$ concentration compared to that of the conventionally housed pigs. However, stearic acid (C18:0) is considered as a neutral fatty acid that has no effect on blood cholesterol (Mahan \& Escott-Stump, 2000). Aside from C18:0, the concentrations of only some of the PUFA differed significantly $(\mathrm{P} \leq 0.05)$ between the two housing systems. Linoleic acid (C18:2n$6)$ was higher $(\mathrm{P} \leq 0.05)$ in the MLL of the free-range pigs $(70.4 \%$ of the total PUFA) compared to the MLL of the conventionally housed pigs (65\% of the total PUFA). The higher C18:2n-6 concentration of the freerange pigs contributed to the higher $(\mathrm{P} \leq 0.05)$ total PUFA concentration of the free-range pigs $(24.65 \%)$ compared to that of the conventionally housed pigs (18.43\%). This finding is consistent with the results of Nilzén et al. (2001). The higher level of this fatty acid in the FR pigs resulted in these animals having a higher calculated sum of $\mathrm{n}-6$ fatty acids $(21.4 \%)$ compared to the Conv pigs $(15.56 \%)$. This also resulted in the FR having the higher $\mathrm{n} 6: \mathrm{n} 3$ ratio $(6.54 v s .5 .44)$. The British Health authority recommends a value closer to 4 (Wiseman, 1997), to amongst others, help prevent coronary heart disease by reducing plasma lipids (Kinsella et al., 1990). In this respect the Conv housed pigs have the more desirable fatty acid profile. Table 4 also shows that the ratios of the total PUFA to SFA of the MLL differed significantly, with a higher $(\mathrm{P} \leq$ 0.05) higher PUFA: SFA ratio for the free-range pigs (0.64) compared to that of the conventionally housed pigs (0.46). Both these ratios lie within the dietary guidelines of the British Committee on Medical Aspects of Food and Nutrition Policy (COMA), who recommend a PUFA: SFA ratio of $>0.45$ and $<1.0$ (as cited by Corino et al., 2002). However, it must be born in mind that a higher PUFA concentration could also result in a softer, oilier fat that could also be more prone to oxidation and rancidity that has negative consequences for human health.

Housing systems had no effect on the mineral composition of the MLL derived from the free-range and the conventionally housed pigs (Table 5). There was a tendency for the MLL derived from the freerange pigs to have a slightly higher concentration of $\mathrm{Cu}, \mathrm{Fe}, \mathrm{Mg}, \mathrm{Na}, \mathrm{P}$ and $\mathrm{Zn}$ compared to that of the conventionally housed pigs. Dworschák et al. (1995) found similar results with regard to the $\mathrm{Zn}$ and $\mathrm{Cu}$ concentration, with higher levels of $\mathrm{Zn}$ and $\mathrm{Cu}(\mu \mathrm{g} / \mathrm{g})$ in the meat from the loin, neck-end and liver of pigs kept in natural farming conditions compared to that of pigs kept in large-scale farming conditions. 
Table 4 Comparison of the means for the fatty acid composition of the $M$. longissimus dorsi (MLL) between the free-range and conventionally housed pigs ( $\%$ by weight of total fatty acids) (Mean \pm s.d)

\begin{tabular}{llll}
\hline \multicolumn{4}{c}{ Housing systems } \\
\hline & Conv $(\mathrm{n}=12)$ & FR $(\mathrm{n}=12)$ & $\mathrm{P}$ \\
\hline C14:0 & $1.32 \pm 0.611$ & $1.45 \pm 0.877$ & 0.663 \\
C16:0 & $23.69 \pm 5.867$ & $23.80 \pm 2.443$ & 0.955 \\
C18:0 & $17.32 \pm 4.492$ & $13.57 \pm 1.342$ & 0.014 \\
C20:0 & $0.02 \pm 0.038$ & $0.02 \pm 0.040$ & 0.983 \\
C22:0 & $0.03 \pm 0.053$ & $0.02 \pm 0.063$ & 0.728 \\
C24:0 & $0.02 \pm 0.056$ & $0.02 \pm 0.039$ & 0.899 \\
\hline C16:1n-7 & $3.33 \pm 2.293$ & $2.59 \pm 1.152$ & 0.340 \\
C18:1n-9 & $35.38 \pm 5.039$ & $33.47 \pm 4.108$ & 0.325 \\
C20:1n-9 & $0.43 \pm 0.215$ & $0.15 \pm 0.143$ & 0.001 \\
C24:1n-9 & $0.05 \pm 0.056$ & $0.28 \pm 0.328$ & 0.019 \\
\hline C18:2n-6 & $11.98 \pm 4.114$ & $17.35 \pm 4.312$ & 0.005 \\
C18:3n-6 & $0.09 \pm 0.132$ & $0.21 \pm 0.142$ & 0.057 \\
C18:3n-3 & $1.11 \pm 0.847$ & $1.22 \pm 0.697$ & 0.722 \\
C20:2n-6 & $1.50 \pm 1.367$ & $1.74 \pm 1.335$ & 0.668 \\
C20:3n-6 & $0.39 \pm 0.284$ & $0.43 \pm 0.329$ & 0.771 \\
C20:4n-6 & $0.84 \pm 0.710$ & $0.70 \pm 1.018$ & 0.683 \\
C20:3n-3 & $0.07 \pm 0.130$ & $0.01 \pm 0.022$ & 0.158 \\
C20:5n-3 & $0.80 \pm 1.045$ & $1.46 \pm 1.707$ & 0.262 \\
C22:2n-6 & $0.04 \pm 0.068$ & $0.06 \pm 0.114$ & 0.524 \\
C22:4n-6 & $0.72 \pm 1.012$ & $0.91 \pm 1.078$ & 0.663 \\
C22:5n-3 & $0.49 \pm 0.468$ & $0.29 \pm 0.231$ & 0.196 \\
C22:6n-3 & $0.39 \pm 0.622$ & $0.29 \pm 0.411$ & 0.646 \\
\hline SFA & $42.39 \pm 7.469$ & $38.88 \pm 2.950$ & 0.159 \\
MUFA & $39.19 \pm 5.763$ & $36.48 \pm 4.057$ & 0.204 \\
PUFA & $18.43 \pm 3.331$ & $24.65 \pm 2.984$ & 0.0001 \\
PUFA:SFA & $0.46 \pm 0.148$ & $0.64 \pm 0.094$ & 0.002 \\
\hline SFA -Sar & &
\end{tabular}

SFA $=$ Saturated fatty acids

MUFA $=$ Mono-unsaturated fatty acids

PUFA $=$ Polyunsaturated fatty acids

PUFA:SFA = Ratio of polyunsaturated to saturated fatty acids

Conv $=$ Conventionally housed pigs

$\mathrm{FR}=$ Free-range pigs

\section{Conclusion}

From the present investigation it can be concluded that the free-range housed pigs had a lower feed intake and slower growth rate than conventionally housed pigs. If pigs are therefore to be housed in a freerange production system, they would have to be retained for a longer period to reach their targeted slaughter weight. An aspect that warrants further research is what the effect of the lice and mosquito bites noted on the free-range pigs would have on meat quality and consumer acceptability, especially when the meat is sold as fresh with the skin intact.

Although the free-range pigs had a lower $\mathrm{P}_{2}$ fat depth and therefore leaner meat, these differences could be attributed to their lighter slaughter body weight and not to the production system. Housing system had no effect on the weight distribution of the commercial cuts (as a percentage of cold carcass weight). The meat from the free-range pigs was slightly more reddish in colour, but apart from that, housing systems had no effect on the WHC of the meat, its initial $\mathrm{pH}\left(\mathrm{pH}_{45}\right)$ or its final $\mathrm{pH}\left(\mathrm{pH}_{24}\right)$. The meat derived from the free-range pigs was just as tender as that of the conventionally housed (indoors) pigs. 
Table 5 Comparison of the means ( \pm s.d.) for the mineral composition of the $M$. longissimus luborum (MLL) between the free-range and conventionally housed pigs ( $\mathrm{mg} / 100 \mathrm{~g}$ meat sample)

\begin{tabular}{llll}
\hline \multicolumn{3}{c}{ Housing systems } \\
\hline & $\mathrm{Conv}(\mathrm{n}=12)$ & $\mathrm{FR}(\mathrm{n}=12)$ & $\mathrm{P}$ \\
\hline $\mathrm{Ca}$ & $4.88 \pm 4.046$ & $2.58 \pm 0.867$ & 0.067 \\
$\mathrm{Cu}$ & $2.42 \pm 2.558$ & $2.55 \pm 4.142$ & 0.930 \\
$\mathrm{Fe}$ & $0.16 \pm 0.118$ & $0.50 \pm 0.802$ & 0.231 \\
$\mathrm{~K}$ & $\operatorname{tr}^{\mathrm{a}}$ & $\operatorname{tr}^{\mathrm{a}}$ & - \\
$\mathrm{Mg}$ & $25.89 \pm 2.106$ & $26.89 \pm 2.325$ & 0.281 \\
$\mathrm{Na}$ & $23.09 \pm 1.956$ & $23.96 \pm 2.366$ & 0.334 \\
$\mathrm{P}$ & $617.91 \pm 64.210$ & $643.60 \pm 46.962$ & 0.275 \\
$\mathrm{~Pb}$ & $0.23 \pm 0.037$ & $0.23 \pm 0.029$ & 0.939 \\
$\mathrm{Zn}$ & $262.35 \pm 27.268$ & $272.56 \pm 81.624$ & 0.685 \\
\hline${ }^{\mathrm{a}} \mathrm{tr}=$ trace $=<0.001 \mathrm{mg} / 100 \mathrm{~g}$ meat sample & \\
$\mathrm{Conv}=$ Conventionally housed pigs & & \\
$\mathrm{FR}=$ Free-range pigs &
\end{tabular}

The moisture, fat, protein and ash content as well as the mineral composition did not differ significantly between the free-range and conventionally housed pigs. However, housing systems did influence the fatty acid composition of the fresh meat. Stearic acid (C18:0) was significantly lower in the meat of the free-range pigs than in the conventionally housed pigs. Higher linoleic acid $(\mathrm{C} 18: 2 \mathrm{n}-6)$ and PUFA concentrations were found in the free-range pigs compared to the conventionally housed pigs. The ratio of n-6:n-3 fatty acids was also such that the Conv housed pigs had the more desirable profile.

The decision whether one should raise pigs in free-range or in conventional systems in South Africa (Western Cape Province) should depend on the market. If the market is willing to purchase meat at a higher price for the assurance that the pigs were raised "under natural conditions", then the free-range production system could be used as a viable alternative. However, it can be concluded that pigs raised in a conventional housing system produced meat with similar quality characteristics to the meat produced from pigs raised in a free-range housing system. Further investigations are required to see what the effect of the housing systems on the commercial processing and intrinsic quality attributes of the processed pork would be.

\section{Acknowledgements}

This study was partly funded by the Elsenburg Agricultural Research Center and by a grant from the Technology and Human Research for Industry Program of the Department of Trade and Industry of South Africa. A.C.M. Kruger and technical personel from the Elsenburg Agricultural Research Center are thanked for management and care of the animals.

\section{References}

AOAC, 1995. Official method of analysis. (16th ed.). Association of Official Analytical Chemists, Inc. Arlington, Virginai, USA:

Barton Gade, P.A., 1987. Meat and fat quality in boars, castrates and gilts. Livest. Prod. Sci. 16, 187-196.

Barton Gade, P.A. \& Blaabjerg, L.O., 1989. Preliminary observations on the behaviour and meat quality of free-range pigs. In: Proc. $35^{\text {th }}$ Int. Conf. Meat Science and Technology, Copenhagen. Denmark. pp. 1002-1005.

Barton Gade, P.A., 2002. Welfare of animal production in intensive and organic systems with special reference to Danish organic pig production. Meat Sci. 62, 353-358.

Beattie, V.E., O'Connell, N.E. \& Moss, B.W., 2000. Influence of environmental enrichment on the 
behaviour, performance and meat quality of domestic pigs. Livest. Prod. Sci. 65, 71-79.

Corino, C., Magni, S., Pagliarini, E., Rossi, R., Pastorelli, G. \& Chiesa, L.M., 2002. Effects of dietary fats on meat quality and sensory characteristics of heavy pig loins. Meat Sci. 60, 1-8.

Dworschák, E., Barna, E., Gergely, A., Czuczy, P., Hóvári, J., Kontraszti, M., Gaál, Ö., Radnóti, L. \& Bíró, G., 1995. Comparison of some components of pigs kept in natural (Free-range) and Large-scale conditions. Meat Sci. 39, 79-86.

Enfält, A.C., Lundström, K., Hansson, I., Lundeheim, H. \& Nyström, P.E., 1997. Effects of outdoor housing and sire breed (Duroc or Yorkshire) on carcass composition and sensory and technological meat quality. Meat Sci. 45, 1-15.

Fisher, P., Mellett, F.D. \& Hoffman, L.C., 2000. Halothane genotype and pork quality. 1. Carcass and meat quality characteristics of three halothane genotypes. Meat Sci. 54, 97-105.

Gentry, J.G., Miller, M.F. \& McGlone, J.J., 2001. Alternative production systems: influence on pig growth and pork quality. Second International Virtual Conference on Pork Quality. pp. 1-7.

Government Notice No. R 1748, 26 June 1992, Regulation Gazette No. 4890. Government Gazette No. 14060. Vol. 324, p. 8.

Hemsworth, P.H., Barnett, J.L., Hofmeyr, C., Coleman, G.J., Dowling, S. \& Boyce, J., 2002. The effects of fear of humans and pre-slaughter handling on the meat quality of pigs. Austr. J. Agric. Res. 53, 493501.

Hoffman, L.C., Vosloo, W.A. \& Mellett, F.D., 1991. Multiple regression equations for the prediction of pig carcass lean and fat yields with practical measurable independent variables. S. Afr. J. Fd. Sci. Nutr. $3(4), 77-80$.

Honikel, K.O., 1998. Reference methods for the assessment of physical characteristics of meat. Meat Sci. 49, 447-457.

Kinsella, J.E., Lokesh, B. \& Stone, R.A., 1990. Dietary n-3 polyunsaturated fatty acids and amelioration of cardiovascular disease: possible mechanisms. Am. J. Clin. Nutr. 52, 1-28.

Lee, C.M., Trevino, B. \& Chaiyawat, M., 1996. A simple and rapid solvent extraction method for determining total lipids in fish tissue. J. AOAC Int. 79, 487-492.

Mahan, L.K. \& Escott-Stump, S., 2000. Krause's food, nutrition and diet therapy. (10th ed.). Pennsylvania: W. B. Saunders Company.

Morrison, W.R. \& Smith, M.L., 1964. Preparation of fatty acid methyl esters and dimethylacetals from lipids with boron fluoride-methanol. J. Lipid Res. 5, 600-602.

Nilzén, V., Babol, J., Dutta, P.C., Lundeheim, N., Enfält, A.-C. \& Lundström, K., 2001. Free-range housing of pigs with access to pasture grazing - effect on fatty acid composition and lipid oxidation products. Meat Sci. 58, 267-275.

Pinta, M., 1982. Modern methods for trace element analysis. (3rd ed.). Ann Arbor, MI: Ann Arbor Science.

SAS, 1990. Statistical Analysis Systems user's guide, Version 8.1. (4th ed.). SAS Institute, Inc., Cary, North Carolina, USA.

Sather, A.P., Jones, S.D.M., Schaefer, A.L., Colyn, J. \& Robertson, W.M., 1997. Feedlot performance, carcass composition and meat quality of free-range housed pigs. Can. J. Anim. Sci. 77, 225-232.

Shapiro, S.S. \& Wilk, M.S., 1965. An analysis of variance test for normality. Biometrika 52, 591-611.

Van der Wal, P.G., Mateman, G., De Vries, A.W., Vonder, G.M.A., Smulders, F.J.M., Geesink, G.H. \& Engel, B., 1993. 'Scharrel' (Free-range) pigs: Carcass composition, meat quality and taste-panel studies. Meat Sci. 34, 27-37.

Warriss, P.D., Kestin, S.C. \& Robinson, J.M., 1983. A note on the influence of housing environment on meat quality in pigs. Meat Sci. 9, 271-279.

Watson, C., 1994. Official and standardized methods of analysis (3rd ed.). The Royal Society of Chemistry, Cambridge.

Windhorst, H.W., 2001. Global patterns of pork production and pork trade. Second International Virtual Conference on Pork Quality. pp. 1-11.

Wiseman, M.J., 1997. Fat and fatty acids in relation to cardiovascular disease: an overview. Br. J. Nutr. 78 (Suppl 1), S3-S4. 